\title{
CORPOS DISSONANTES: SOBRE A EMERGÊNCIA DE UMA PEDAGOGIA INTERCULTURAL “QUEER/CUIR/CU”
}

\author{
André Vítor Brandão da Silva ${ }^{1}$
}

\begin{abstract}
Resumo
Este artigo investiga de que forma as questões de gênero interferem nos processos de letramento dos sujeitos que não se apresentam sob o domínio hétero-cis-normativo. $\mathrm{O}$ trabalho aponta para a emergência da construção de um letramento intercultural "Queer/Cuir/Cu" que possa operar no campo da valorização das diferenças, promovendo uma ação pedagógica contextualizada que auxilie no desenvolvimento das potencialidades e especificidades de ser/estar no mundo de cada aluno. Para tal, utilizamos enquanto estratégia metodológica a entrevista compreensiva que, por sua vez, foi realizada com Maya Coelly - mulher trans que vive e trabalha em Petrolina-PE - a fim de colher narrativas pessoais para entender com mais clareza o cotidiano escolar opressor que é imposto às pessoas transgêneras.
\end{abstract}

Palavras-chave: Letramento. Corpo. Gênero. Interculturalidade. Queer.

\section{DISSONANT BODIES: ON THE EMERGENCY OF A "QUEER / CUIR / CU" INTERCULTURAL PEDAGIGY}

\begin{abstract}
This article investigates how gender issues interfere in the literacy processes of subjects who do not present themselves under the hetero-cis-normative domain. The work points to the emergence of the construction of an intercultural literacy "Queer / Cuir / $\mathrm{Cu}$ " that can operate in the field of valuing differences, promoting a contextualized pedagogical action that assists in the development of the potentialities and specificities of being in the world of each student. To this end, we used as a methodological strategy the comprehensive interview which, in turn, was conducted with Maya Coelly - trans woman who lives and works in Petrolina-PE - in order to gather personal narratives to understand more clearly the oppressive school daily life that is imposed on transgender people.
\end{abstract}

\footnotetext{
${ }^{1}$ Mestrando do Programa de Pós-Graduação Mestrado em Educação, Cultura e Territórios Semiáridos (PPGESA) pela Universidade do Estado da Bahia (UNEB), pós-graduado em Dança Educacional e Artes Cênicas pela Faculdade São Fidelis e Licenciado em Artes Visuais pela Universidade Federal do Vale do São Francisco (Univasf). Também artista e arte educador.
} 
Keywords: Literacy. Body. Genre. Interculturality. Queer.

\section{CUERPOS DISSONANTES: SOLBRE LA EMERGENCIA DE UMA PEDAGOGÍA INTERCULTURAL “QUEER / CUIR / CU”}

\section{Resumen}

Este artículo investiga de qué forma las cuestiones de género interfieren en los procesos de literacía de los sujetos que no se presentan bajo el dominio hetero-cis-normativo. El trabajo apunta a la emergencia de la construcción de un literacía intercultural "Queer/Cuir/Cu" que pueda operar en el campo de la valorización de las diferencias promoviendo una acción pedagógica contextualizada que auxilie en el desarrollo de las potencialidades y especificidades de ser / estar en el mundo de cada aluno. Con este fin, utilizamos como estrategia metodológica la entrevista integral que, a su vez, se realizó con Maya Coelly, una mujer trans que vive y trabaja en Petrolina-PE, con el fin de reunir narraciones personales para comprender más claramente la opresiva vida cotidiana de la escuela. impuesta a las personas transgénero.

Palabras clave: Alfabetización. Cuerpo. Género. Interculturalidad. Queer.

\section{Descortinando caminhos: uma introdução}

De que forma apreendemos e nos situamos no mundo? Pergunta aparentemente simples, mas que pressupõe uma infindável teia de relações que tencionam diversas dimensões da vida humana. Contudo, essa indagação evoca com mais ênfase a Educação, ou melhor, os processos de ensino-aprendizagem que tentam dar conta da forma pela qual entendemos e sentimos o mundo.

O artigo 205 da Constituição brasileira de 1988 diz que, "A educação, direito de todos e dever do Estado e da família, será promovida e incentivada com a colaboração da sociedade, visando ao pleno desenvolvimento da pessoa, seu preparo para o exercício da cidadania e sua qualificação para o trabalho" (BRASIL, 1988, n. p.). Desse modo, está assim descrito, que a Educação, em primeira instância, se voltaria para o desenvolvimento do sujeito enquanto pessoa humana, como cidadão.

Entretanto, a Educação na atualidade tem se direcionado, prioritariamente, para a formação de mão de obra especializada para o trabalho e não para o ser individual/coletivo atuante na sociedade. Deriva-se dessa deturpação uma massa de indivíduos acríticos, facilmente manipulados pela elite política do país. Política essa, 
que pode ser adjetivada como branca, heteronormativa e advinda de classes abastadas. É no corpo que essa política encontra lugar de materialização, que desenvolve mecanismos de controle e triunfa seu domínio sobre as sexualidades, as identidades, os discursos e os gestos.

Segundo Foucault (1987):

Aprender a comportar-se, movimentar-se, ser preciso e ter ritmo. Gestos são fabricados, e sentimentos são produzidos. Este adestramento é resultado da aplicação de técnicas positivas de sujeição baseadas em saberes pedagógicos, médicos, sociológicos, físicos etc. O corpo torna-se útil e eficiente, mas ao mesmo tempo torna-se dócil e submisso: o corpo só se torna força útil se é ao mesmo tempo corpo produtivo e corpo submisso (FOUCAULT, 1987, p. 28).

A atual Educação brasileira baseada no modelo de aquisição de habilidades e competências carrega consigo um ideal disciplinatório dos corpos - como descrito por Foucault - atuando não somente na esfera corporal individual, mas também no corpo social. Por isso, manter os corpos docilizados e submissos se faz questão primordial para a manutenção de poderes hegemônicos.

Dessa maneira, este artigo se situa na emergência da criação de uma Educação contemporânea que tenha como enfoque a multiplicidade de modos de ser/estar no mundo e que não seja regida por ideais de manutenção de poderes que segregam os corpos, as inteligências e, sobretudo, a vida. Para tal, percorreremos algumas proposições que acreditamos serem lugares potentes para empreendermos essa mudança. Situam-se nesse espaço, as ideias em torno do Letramento Ideológico, da Interculturalidade e da Teoria Queer.

Por sua vez, a Teoria Queer será utilizada neste artigo como Queer/Cuir/Cu em consonância com o pensamento que vem se desenvolvendo no contexto latino americano sobre a necessidade de reformulação desse conceito. Nesse sentido, Pereira (2012, p. 371) nos indaga que: "Haveria possibilidade de o gesto político queer abrir-se para saberes-outros ou estaríamos presos dentro de um pensamento sem que nada de novo possamos propor ou vislumbrar? Como, enfim, pensar queer nos trópicos?". Destarte, tal questão abre o debate da necessidade de pensarmos essa teoria a partir das especificidades da América Latina.

Assim, a ideia de contexto se faz urgente, tendo em vista que esse é multidimensional e repleto de tensões e assimetrias de poder. Nessa perspectiva, é que a 
pesquisa adota uma abordagem etnográfica, pois, utiliza narrativas pessoais colhidas em entrevistas realizadas com Maya Coelly, mulher trans que vive em Petrolina-PE. No desenvolver desse trabalho de cunho etnográfico, analisaremos os contextos e as problemáticas que envolveram as práticas de letramento de Maya Coelly nos anos em que esteve na escola.

Destarte, como análise da discussão, propomos neste texto, a construção de processos de letramento basilados na perspectiva educacional da Interculturalidade que possam, assim, subsidiar uma pedagogia $Q u e e r / C u i r / C u$ em que as questões de gênero estejam em posições privilegiadas e na qual os corpos atuantes nesses processos educativos sejam admitidos em suas diferenças.

\section{Apontamentos e reflexões para processos de letramento possíveis}

Os processos educativos da nossa atual sociedade quase sempre se situam na problemática da aquisição da leitura e da escrita. Assim sendo, podemos perceber que boa parte do ocidente tem como principal meio de relação e comunicação, a leitura e a escrita, ou seja, a vida é quase em sua totalidade mediada pela palavra escrita. Logo, o aprendizado da escrita corresponde a "[...] aprender a utilizar os recursos da escrita num conjunto de tarefas e procedimentos definidos pela cultura" (OLSON, 1997, p. 60).

Surge, portanto, a ideia de Letramento como sendo o processo pelo qual os sujeitos são submetidos à aquisição da leitura e da escrita, assim como, aos usos desses recursos em nossa cultura. Street (2006) sugere que, ao invés de pensarmos em Letramento como sendo um todo uniforme e unívoco, pensemos no termo "práticas de letramento", suscitando a existência de modos de apreensão da leitura e da escrita em diversos contextos. Nesse ponto, o autor (2006) propõe a existência de um letramento autônomo e outro ideológico, ambos instaurando diferentes modos de apreensão da realidade.

No que concerne ao Letramento de caráter autônomo, o mesmo desenvolve processos técnicos de aquisição da leitura e da escrita com objetivos bastante específicos para que os sujeitos atuem na sociedade de modo eficaz. Sendo assim, desconsidera o contexto e as especificidades dos sujeitos, pois se organiza a partir de um modelo autoritário e homogeneizante. Esse tipo de letramento funciona enquanto manobra de controle, haja vista que articula em seus processos componentes de subordinação. O modelo autônomo impõe certos valores culturais e morais exteriores 
aos sujeitos participantes do processo de letramento na tentativa de construção de um contexto uniforme de dominação.

Por sua vez, o letramento ideológico se constitui a partir dos contextos em que irá atuar, assim, não se coloca de forma impositiva na medida em que se constrói em consonância com os sujeitos que dele participarão. Em defesa do modelo ideológico, Street (2006) afirma que:

Prefiro trabalhar com base no que chamo de modelo "ideológico" de letramento, o qual reconhece uma multiplicidade de letramentos; que o significado e os usos das práticas de letramento estão relacionados com contextos culturais específicos; e que essas práticas estão sempre associadas com relações de poder e ideologia: não são simplesmente tecnologias neutras (STREET, 2006, p. 466).

Dessa maneira, podemos pensar que, para construirmos um processo pedagógico que valorize as culturas dos alunos, assim como suas identidades, seja preciso adotar práticas de letramento consonantes com o modelo ideológico para, assim, construir uma educação intercultural que estabeleça processos de ensino-aprendizagem menos excludentes.

\section{Uma urgência no mundo contemporâneo: a interculturalidade}

A contemporaneidade se apresenta para nós como campo privilegiado para o surgimento de brechas por onde escapam diversos modos de existir. As identidades na atualidade não se deixam ser contidas e escapam com frequência de toda e qualquer investida que tente encarcerá-las. Nesse panorama, surge a emergência da interculturalidade como campo propício para a coexistência das culturas.

A interculturalidade diz respeito à associação de duas ou mais culturas que se relacionam de modo horizontal e simultâneo. Essa abordagem parte do pressuposto do respeito e da cooperação, mas entende que os conflitos entre as culturas são inevitáveis. A interculturalidade enxerga as divergências como parte indispensável da vida em sociedade. Desse modo, as fronteiras entre as culturas não são estáticas e intransponíveis, mas porosas e móveis e, em vista disso, negociam seus espaços sem inferirem sobre as outras condutas autoritárias, impondo relações assimétricas de poder. 
No campo da Educação, a perspectiva intercultural atua de maneira a promover espaços de coexistência e valorização das diferenças. Como comentam Santiago, Akkari e Marques (2013):

Uma primeira postura incontornável nesse processo é inverter o discurso dominante quando se trata de falar sobre as diferenças culturais na escola. Trata-se de mudar as representações, as concepções de diferença cultural como um problema (fardo, perturbação, transição), pela diferença cultural como uma oportunidade (recurso, identidade, enriquecimento) [SANTIAGO; AKKARI; MARQUES, 2013, p. 160].

A diferença se sobressai como aspecto deveras importante para a interculturalidade, pois é a partir dos conflitos que dela derivam que pontos de vista e discursos divergentes podem ser colocados, revistos, e reelaborados para a construção de outras possibilidades de identidades e existências em grupo. Desse modo, segundo Hall $(2014$, p. 14) "[...] as sociedades da modernidade tardia, são caracterizadas pela "diferença"; elas são atravessadas por diferentes divisões e antagonismos sociais que produzem uma variedade de "posições de sujeito" - isto é, identidades - para os indivíduos".

Outra questão cerne da perspectiva intercultural é a ideia de contexto, o qual Marques (2016, p. 8) entende como sendo o lugar “[...] onde o texto transborda em significados e sentidos; onde ele é autorizado a ser enunciado; onde ele se organiza e se traveste, ocultando, às vezes, o seu verdadeiro sentido. No fundo é um ambiente onde o texto se manifesta”. O contexto, dessa maneira, se apresenta multidimensional, ele não é de natureza simplista e não demonstra apenas as relações que os indivíduos estabelecem com seu entorno, mas existe repleto de camadas internas que, inevitavelmente, se interrelacionam a partir de sistemas de poder que, na maioria das vezes, se justapõem em seu interior.

Nesse sentido é que a ideia de interculturalidade nos fornece caminhos para pensarmos na construção de uma pedagogia $Q u e e r / C u i r / C u$, na medida em que valoriza as especificidades dos contextos e organiza os sistemas de poder presentes nos corpos de modo horizontal. Isso posto, para além de apenas fornecer aos sujeitos possibilidades para aquisição da leitura e da escrita, o letramento ideológico, na perspectiva Intercultural, possibilita leituras de mundo, assume posturas éticas em relação aos outros que compõem nossa coletividade. 


\section{A polifonia dos corpos: vozes (in)visíveis}

Todo e qualquer corpo existe em sua potência política. É no/pelo corpo que o mundo adquire concretude, é onde nossa existência se encarna de modo complexo e entrincheirado. Nessa trincheira que envolve, sobretudo, as identidades, é que a corpopolítica $^{2}$ se revela. Muitas vezes, essa política se mostra de modo autoritário, imprimindo sobre o corpo um estado de controle em prol da manutenção de poderes estabelecidos.

Todavia, existem aqueles corpos que ousam se situar nas margens do desvio, em lugares que a pretensa hegemonia das identidades que a sociedade cis-heteronormativa $^{3}$ aceita nem é capaz de imaginar. E na dificuldade de lidar com a polifonia de corpos da contemporaneidade, é que esta sociedade cria mecanismos de invisibilidade, empurrando esses corpos desviados, cada vez mais, para as margens do abismo da marginalidade. Daí, a importância de pensarmos na corpopolítica, pois como comenta Gadelha (2018, p. 32), o corpo “[...] se constitui como superfície política perpassada pelos anseios de uma cultura da sexualidade reprodutiva em que se afirma e reforça a heteronormatividade, em descompasso com outros destinos e possibilidades de existências para esses corpos".

A Educação como lugar no qual esses corpos apreendem e se situam no mundo acaba funcionando também como lugar de controle. Foucault (1987) já colocava essa questão em seu livro "Vigiar e Punir", no qual a escola, enquanto instituição, edifica sistemas de controle e disciplinamento dos corpos. É nesse ambiente educacional que algumas existências serão visibilizadas e outras invisibilizadas por conta de sua natureza disruptiva em relação ao já estabelecido.

Nesse jogo de aparecer e apagar, os processos de letramento incidem sobre os corpos de maneira determinante, pois trazem consigo discursos e pensamentos arraigados, que servem apenas à classe dominante. Dessa maneira, o letramento autônomo, no qual a educação brasileira é baseada, homogeniza os processos de ensinoaprendizagem, que não consideram os contextos e as especificidades de cada aluno, além de estarem fundamentados apenas em funções técnicas de aquisição da leitura e da

\footnotetext{
${ }^{2}$ Termo criado pelo pesquisador Kaciano Gadelha (2018) baseado no termo "body politics" de Judith Butler presente no livro "Problemas de Gênero" (2003), da autora.

3 Refere-se à constatação de que em nossa sociedade a heteronormatividade e a cisgeneridade são obrigatoriamente impostas a todos os sujeitos.
} 
escrita. Nesse tipo de letramento, os corpos que não se encaixam são colocados à margem do processo, suas vozes são silenciadas e suas imagens apagadas.

A construção de um Letramento Intercultural Queer/Cuir/Cu nos fornece uma possibilidade de criar rupturas no cenário descrito anteriormente, já que aponta para outra maneira de organizar seus processos educacionais, considerando os diversos contextos que envolvem os indivíduos participantes do processo. As identidades de gênero, nesse tipo de letramento, são postas na superfície, e podem, inclusive, serem norteadoras para o desenvolvimento dos processos de ensino-aprendizagem.

\section{Falar de / falar com: a abordagem etnográfica como forma de conhecimento e aproximação com o outro}

No exercício de construção dessa proposição pedagógica Queer/Cuir/Cu nos surge uma questão deveras salutar na atualidade, e que tem gerado discussões nos mais diversos círculos sociais, que é a questão do Lugar de Fala, pois, “[...] o falar do outro foi muitas vezes visto - e de fato praticado - como falar pelo outro, no lugar do outro" (MORAES, 2017, p. 13).

E nessa condição de estar me referindo à existência de outras pessoas, além da minha, convidei para ajudar-me na escritura desse artigo Maya Coelly, mulher trans que vive e trabalha na cidade de Petrolina-PE. Através da observação do cotidiano no salão de beleza onde trabalha, de relatos a mim confidenciados por ela e escritos em meu diário de campo, pude constatar diversas problemáticas que envolvem a Educação e as questões de gênero.

Maya Coelly é proprietária de um salão de beleza localizado em um bairro periférico da cidade de Petrolina-PE chamado Cohab VI. Ela passa a maior parte do dia trabalhando em seu salão, que é sua principal fonte de renda. Maya é deveras amorosa e simpática, tem cabelos longos e corpo sinuoso. Seu local de trabalho é espaçoso e aconchegante, com sofás, espelhos, pinturas abstratas nas paredes e prateleiras com produtos para os procedimentos que realiza nos cabelos das clientes. Nos móveis, em meio as escovas e pincéis capilares existe uma série de revistas, em sua grande maioria da "Caras" e da "Veja". As edições dessas revistas não são recentes e demonstram que o objetivo principal de estarem ali é a distração das clientes enquanto estão em atendimento. Essa questão revela uma das facetas do modelo autônomo de letramento, na medida em que têm seus usos restritos à aquisição pragmática da leitura e da escrita 
não favorecendo, assim, o despertar de um interesse de conhecer e experienciar o mundo através da leitura, mas somente, como no exemplo acima, tê-la como uma distração momentânea, uma ocupação banal do tempo.

Foi na cidade de Sobradinho-BA que Maya Coelly nasceu e cursou até o terceiro ano científico - como ela mesma coloca quando fala sobre esse assunto. Ainda sem ter feito a transição ${ }^{4}$, ela se recorda de alguns problemas que enfrentava por não seguir as regras impostas a ela. Problemas como: "Eu só ia ao banheiro quando estávamos em aula, pois não me sentia confortável em ir com outras pessoas lá" ou "Eu precisava ser muito boa em todas as matérias para poder ficar fora da mira dos apelidos e comentários homofóbicos".

A primeira questão colocada por Maya Coelly abre um debate que vem ganhando força nos últimos anos, que é a questão dos banheiros como uma das facetas das "Tecnologias de gênero". Preciado (2018) comenta que:

No século 20, os banheiros viraram autênticas cédulas públicas de inspeção, nas quais se avalia a adequação de cada corpo com os códigos vigentes de masculinidade e feminilidade. Na porta de cada banheiro há um único sinal, uma interpelação de gênero: masculino ou feminino, damas ou cavalheiros, chapéu masculino ou chapéu feminino, bigode ou florzinha, como se a ação de entrar no banheiro fosse mais para refazer o gênero do que para se desfazer da urina e da merda (PRECIADO, 2018, p. 56- 57).

O que Preciado (2018) nos coloca é indispensável para pensarmos no que Maya Coelly nos fala, pois, como não está sob o domínio do binarismo de gênero, o banheiro se torna uma estrutura de disciplinamento dos corpos, impondo aos sujeitos desconforto com suas identidades. Para a efetivação de uma pedagogia $Q u e e r / C u i r / C u$, as mudanças arquitetônicas seriam essenciais, pois, como descrito acima, são segregadoras.

No que concerne à segunda questão colocada por Maya Coelly, que diz respeito à estratégia de obter sucesso e aprovação nas disciplinas escolares, resultante do fato de que o seu bom desempenho na escola acabava se sobressaindo à sua identidade de gênero, sob a ótica daqueles que a discriminavam, ela se mostrava útil. Dessa maneira, Maya Coelly conseguia afastar os potenciais homofóbicos que não a agrediam pelo fato de que precisavam de suas habilidades intelectuais, como ela bem nos fala em uma entrevista realizada em seu salão de beleza: "Eles não tiravam "onda" comigo pelo fato

\footnotetext{
${ }^{4}$ Palavra utilizada para designar o processo de reivindicação do reconhecimento social e legal como mulher.
} 
de que iam precisar que eu passasse "cola" na hora da prova, ou então iam me pedir ajuda para os trabalhos da escola".

Isso, nos remonta as ideias de Foucault (1987, p. 197) sobre as relações entre o capitalismo e o disciplinamento dos corpos e como as noções de produção são determinantes para o mover dos sujeitos em sociedade, pois "A fábrica, a escola, a prisão ou os hospitais têm por objetivo vincular os indivíduos ao processo de produção; trata-se de garantir a produção em função de uma norma determinada". Assim, sendo protagonista na sala de aula e se constituindo como sujeito eficiente na produção de conhecimento, Maya Coelly se blindava das iminentes agressões. Logo, sua identidade de gênero era aceita, já que ser alguém produtivo é muito valioso para o mundo capitalista.

Nesse ponto, podemos perceber, mais uma vez, a presença dominante do modelo de letramento autônomo, pois este modelo acaba por abrir espaço para divisões e diferenciações em sala de aula, visto que aquele que consegue absorver mais conteúdos e ser bem avaliado nos exames de qualificação se torna um aluno bem sucedido, enquanto aqueles que não conseguem são tidos como alunos ruins. No modelo de letramento autônomo, os contextos socioculturais não são considerados em detrimento da obtenção pragmática das capacidades de ler e escrever. Consequentemente, Maya Coelly sendo submetida a esse modelo de letramento tem sua relação com a leitura e a escrita restrita às funções básicas da comunicação.

A transição é outra questão conflituosa. Maya Coelly nos relata que "Esperei terminar o terceiro grau científico para tomar hormônio e fazer a transição". Isso posto, podemos pensar que a Educação como instituição normativa e disciplinar funciona também como uma "Tecnologia de gênero". Seria, portanto, uma tecnologia social heteronormativa que "[...] pode ser caracterizada como uma máquina de produção ontológica que funciona mediante a invocação performativa do sujeito como corpo sexuado" (PRECIADO, 2017, p. 28).

Assim, em toda sua estrutura, a Escola privilegia e demarca os lugares dos "homens" e das "mulheres" seja nos banheiros, nas filas para o lanche, nos jogos de futebol para os meninos e na ginástica para as meninas. Desse modo, Maya Coelly só foi "autorizada" a fazer a transição quando se colocou fora dos muros da escola. Destarte, não se sentindo parte dos processos de ensino-aprendizagem, Maya Coelly não se relacionou mais com a escola, vendo esse lugar como hostil e distante. Preferiu, 
assim, seguir sua profissão de cabeleireira que é onde pode se exercer como mulher trans e sofrer menos (tipos de) discriminação por isso.

\section{Pela construção de uma pedagogia $Q u e e r / C u i r / C u$ : desafios de um enunciado}

Quando colocamos a emergência de construção de uma Pedagogia Intercultural Queer/Cuir/Cu, reclamamos na verdade, a edificação de processos de letramento que incluam as questões que emergem do corpo e das relações que esse estabelece com o mundo. A questão de gênero, tendo o corpo como lugar de construção e morada deveria, em tese, ser debate central na Educação; entretanto, vem sendo constantemente tolhida pelos poderes institucionalizados de nossa sociedade.

Podemos citar como exemplo, a Lei $\mathrm{n}^{\mathrm{o}} 2.985^{5}$ de 19 de dezembro de 2017 do município de Petrolina-PE, que proibiu no currículo e no ensino das escolas municipais da cidade questões de gênero e sexualidade. Essa Lei materializa um pensamento conservador e dominante que vem se fortalecendo e se institucionalizando no Brasil nas últimas décadas. Consequentemente, estamos todos os dias testemunhando o ruir de muitas conquistas dos grupos minoritários em prol da manutenção de poderes de submissãoo.

Surge, portanto, a seguinte questão: Que caminhos precisamos percorrer para a construção de uma pedagogia Queer/Cuir/Cu? Em primeira instância é preciso entender que o corpo se faz enquanto território de conflito em que atuam diversas forças e poderes, assim como admiti-lo em toda sua diferença, sobretudo, no que tange as sexualidades e as questões de gênero. Teríamos, também, que desenvolver processos de ensino-aprendizagem que não estejam enlaçados em diretrizes fixas que visem à aquisição de habilidades e competências, mas que sejam fundamentados na ideia de promover ações educativas para o entendimento do mundo em sua complexa diversidade.

Para entendermos um pouco mais sobre os desafios dessa proposição, precisamos pensar sobre a denominação dessa proposta. A nomenclatura $Q u e e r / C u i r / C u$

\footnotetext{
5 O texto na íntegra da lei pode ser acessado pelo endereço eletrônico: <http://doem.org.br/pe/Petrolina/diarios/previsualizar/xoN82DjZ?filename=DOE-pe_petrolina-ed.1812ano.7.pdf\&_cb=20171220190758>
} 
surge como possibilidade de pensar a teoria Queer no contexto latino americano, pois, como comenta Pereira (2006)

A expressão queer, utilizada como forma de autodesignação repetindo e reiterando vozes homofóbicas que assinalam a abjeção daquele que é denominado queer, mas descontextualizando-as desse universo de enunciação, já que se atribui valores positivos ao termo transformando-o numa forma orgulhosa de manifestar a diferença -, pode ocasionar uma inversão da cadeia de repetição que confere poder às práticas autoritárias precedentes, uma inversão dessa historicidade constitutiva. Algo novo surgiria, então, desse processo, anunciando a irredutibilidade e expressando a incômoda e inassimilável diferença de corpos e almas que teimam em se fazer presentes (PEREIRA, 2006, p. 469).

No contexto brasileiro, a palavra queer não soa como algo pejorativo, e por esse motivo não atua enquanto potência política. Destarte, foneticamente a pronuncia da palavra Queer pode ser escrita como Cuir e simplificada para $\mathrm{Cu}$, numa tentativa de politizar o termo. Dessa maneira, Altmayer (2018) discorre que:

Cuir, quando lido em português, também remete ao cu, como acesso àquilo mantido escondido. É nesse sentido que Larissa Pelúcio sugere tratar os estudos queer como estudos cu, em uma tradução provocadora, pouco palatável, para que o campo se abra para novas possibilidades de contestação (ALTMAYER, 2018, p. 39).

Levando em consideração que o Brasil é um dos países com maior demonstrativo de violência direcionada a comunidade LGBTQIA ${ }^{6}$, trazer essas questões para o ambiente escolar é de extrema importância para a construção de um mundo menos violento e segregador. Assim, empreender uma Pedagogia Queer/Cuir/Cu na escola é gesto político de desarticulação de poderes, um exercício de alteridade, assim como de descolonização dos corpos.

A proposta dessa pedagogia é pensar nos contextos em deslocamento dos alunos, lançando atenção para a potência iminente dos encontros, tendo em vista que os aprendizados do mundo acontecem, prioritariamente, através do corpo, da potência de encontrar com o outro e daí se reconhecer como igual e diferente.

Não é tarefa fácil desenvolver uma Educação numa perspectiva $Q u e e r / C u i r / C u$, tendo em vista que, ela cria fissuras e expõe questões muitas vezes invisibilizadas pela

\footnotetext{
${ }^{6}$ Sigla para: Lésbicas, Gays, Bissexuais, Transgêneros, Transexuais, Travestis, Queers, Questionandos, Intersexuais, Assexuais, Aliados e outras sexualidades e identidades de gênero ainda não incluídas.
} 
sociedade hetero-cis-normativa ${ }^{7}$ na qual vivemos. E nesse modelo de sociedade, o “estranho/queer" não é aceito, pois ele enseja uma existência outra que escapa das regras que lhe são impostas.

\section{Algumas considerações abertas, não finais e nada conclusivas}

As proposições apresentadas nesse texto não são recentes, contudo, estão em ascensão no campo da Educação, e são feitas na atualidade como palco para fomentar discussões acirradas nos mais diversos campos da nossa sociedade. Longe de pretensamente dar conta de discussões tão amplas, fizemos aqui um recorte e apontamos para algo que possa trilhar caminhos fecundos em busca de uma Educação mais justa e igualitária.

A emergência de uma pedagogia Queer/Cuir/Cu é plausível e potente. Ela abre um cem números de problemáticas que se esparram tentaculares a nossa frente, nos demandando uma série de articulações político-teóricas que exigem, sobretudo, o exercício de se (re)conhecer no outro, de entender as necessidades daqueles que estão em nossa volta.

A Educação sob a perspectiva da interculturalidade se faz enquanto terreno propício à construção de uma pedagogia alicerçada nos processos de letramento ideológico e elas, por sua vez, geram procedimentos de ensino-aprendizagem que promovem o desenvolvimento das diversas identidades presentes nos corpos dos sujeitos.

Como explicitado no enunciado dessa seção, o pensamento que desenvolvemos aqui está aberto e não se figura como finalizado dada a própria natureza dos objetos de estudo - o corpo, a Educação e as questões que deles emergem - que, no que lhes concerne, são mutáveis e fluídos.

\section{Referências bibliográficas}

ALTMAYER. G. Apontamentos para uma cartografia: o cuir/queer como território em expansão. In: Revista Select. ano 7, ed. 38. São Paulo: 2018.

BRASIL. Constituição da República Federativa do Brasil de 1988. Brasília, DF: Senado Federal: Centro Gráfico, $1988 . \quad$ Disponível em:

\footnotetext{
${ }^{7}$ Termo utilizado para explicitar o fato de que em nossa sociedade a heterossexualidade e cisgeneridade nos são impostas.
} 
<https://www.senado.leg.br/atividade/const/con1988/CON1988_05.10.1988/art_205_.a sp>_Acesso em: 29 jun. 2018.

FOUCAULT, M. Vigiar e punir. Petrópolis: Vozes, 1987.

GADELHA. K. Corpopolítica: errâncias poéticas decolonializando roteiros. In: SESC. Palco Giratório 2018. Sesc: Departamento Nacional, 2018.

HALL. S. A identidade cultural na pós-modernidade. $12^{\mathrm{a}}$ ed. Rio de Janeiro: Lamparina, 2014.

MARQUES, Juracy. Educação descontextualizada: desexplicando as explicações. In: PINZOH, J.M; REIS, S. E. O paradigma cultural: interfaces e conexões. Curitiba: Editora CRV, 2016.

MORAES. F. Falar de, falar por, falar com. In: Todos os gêneros: mostra de arte e diversidade. São Paulo: Itaú Cultural, 2017.

OLSON, D. R. O mundo no papel: as implicações conceituais e cognitivas da leitura e da escrita. Tradução: Sérgio Bath. Revisão técnica: Rodolfo Ilari. São Paulo: Ática, 1997.

PEREIRA, P. P. G. A teoria queer e a reinvenção do corpo. In: Cadernos Pagu, 2006. Disponível em: http://www.scielo.br/scielo.php?script=sci_arttext\&pid=S010483332006000200020. Acesso em: 18 jun. 2019.

PEREIRA. G. Queer nos trópicos. In: Contemporânea. São Paulo: v. 2, n.2, jul.- dez. 2012, p. 371- 394.

PRECIADO. P, B. Manifesto Contrassexual: práticas subversivas de identidade sexual. N 1, São Paulo, 2017.

PRECIADO. P, B. Lixo e Gênero, Mijar/Cagar, Masculino/Feminino. In: Revista Select. ano 7, ed. 38. São Paulo, 2018.

SANTIAGO, M; AKKARI, A; MARQUES, L. P. Educação intercultural: desafios e possibilidades. Petrópolis, RJ: Vozes, 2013.

STREET. B. Perspectivas interculturais sobre o letramento. In: Filosofia e Linguística Portuguesa. n. 8, São Paulo, 2006, p. 465- 488. 